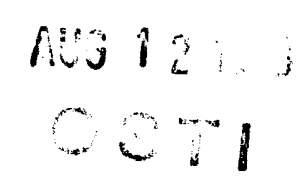

GAS EVOLUTION FROM COAL IN SEALED GLASS AMPOULES

by

Karl s. Vorres

Chemistry Division, Building 211

Argonne National Laboratory

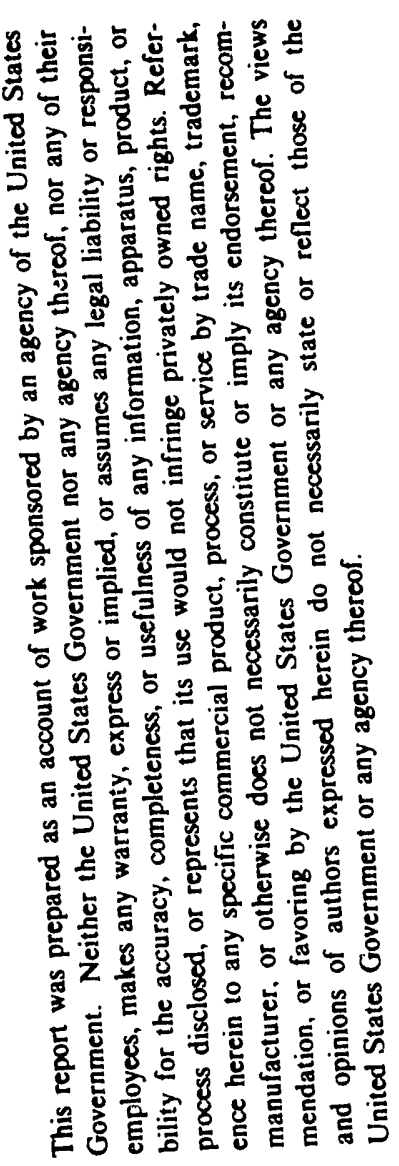

Argonne, II 60439

for presentation at

Fuel Chemistry Division

American Chemical society

$204 \mathrm{TH}$ National Meeting

Washington, DC

August 23-28, 1992

The submitted manuscript has been authored

by a contractor of the U.S. Government

under contract No. W.31-109ENG-38.

Accordingly, the U.S. Government retains a

nonexclusive, royalty-free license to publish

nonexclusive, royaley-free license to publish
or reproduce the published form of this

or reproduce the published form of this
contribution. or allow others to do so, for

U. S. Government purposes. 


\title{
GAS EVOLUTION FROM COAL IN SEALED GLASS AMPOULES*
}

\author{
K. S. Vorres \\ Chemistry Division, Building 211, Argonne National Laboratory \\ Argonne, IL 60439, USA
}

\section{INTRODUCTION :}

Earlier publications reported studies on the gas content of Argonne premium Coal samples $(1,2)$. These samples are available in ampoules of 5 grams of -100 mesh and 10 grams of -20 mesh. They were periodically opened in vacuum and analyzed with a mass spectrometer as part of a quality monitoring program. The samples were originally sealed under nitrogen in a glove box maintained at less than $40 \mathrm{ppm}$ of oxygen. Moisture present in the coal was kept in the samples as much as possible. Determinations of the gases were made and provide an opportunity to observe the changes due to transformations, release of dissolved gases or other processes in the samples. Changes in the gas content were observed and may be useful in interpreting a variety of phenomena.

The eight Argonne Premium coal samples are described below:

$\begin{array}{lllllll}\# & \text { Name } & \text { Rank } & \text { State } & \text { Dmmf C } & \text { Dmmf H Abbrev. } \\ 1 & \text { Upper Freeport } & \text { MVB } & \text { PA } & 88.08 & 4.84 \text { UF } \\ 2 & \text { Wyodak-Anderson } & \text { SUB } & \text { WY } & 75.01 & 5.42 \text { WY } \\ 3 & \text { Illinois \#6 } & \text { HVB } & \text { II } & 77.67 & 5.20 \text { IL } \\ 4 & \text { Pittsburgh } & \text { HVB } & \text { PA } & 83.20 & 5.43 \text { PITT } \\ 5 & \text { Pocahontas \#3 } & \text { LVB } & \text { VA } & 91.05 & 4.48 \text { POC } \\ 6 & \text { Blind Canyon } & \text { HVB } & \text { UT } & 80.69 & 5.81 \text { UT } \\ 7 & \text { Lewiston-Stockton } & \text { HVB } & \text { WV } & 82.58 & 5.44 \text { WV } \\ 8 & \text { Beulah-Zap } & \text { LIG } \text { HD } & 74.05 & 4.90 \text { ND }\end{array}$

LVB $=$ Low volatile bituminous, MVB = Medium volatile bituminous, HVB $=$ High volatile bituminous, SUB = subbituminous, LIG = Lignite, state = U. S. A. State of oxigin, Dmmf = dry mineral matter-free, Abbrev = Abbreviation used later

\section{EXPERIMENTAL:}

The Argonne premium coal samples have been sealed in borosilicate glass ampoules in a nitrogen atmosphere (3). A hydrogen-oxygen torch was used for the sealing. The hydrogen and oxygen gas flows were controlled with a gas mass flow controller to maintain stoichiometric conditions during the sealing. The oxygen content of the glovebox system was constantly monitored during the operation and no significant deviations from the expected values were observed.

\footnotetext{
*This work was supported by the office of Basic Energy sciences, Division of Chemical Sciences, U. S. Department of Energy, under contract number W-31-109-ENG-38.
} 
A supply of coal ampoules for each of the eight samples in each of the two mesh sizes was selected to provide samples for analysis over several years at initial sample consumption rates of about two per year. The ampoules were sent to the Analytical Chemistry Laboratory of the Argonne National Laboratory for gas analysis. The ampoules were placed in an evacuable chamber and the surrounding air was pumped out. A magnetic hammer was used to break the ampoule and release the atmosphere above the ampoules.

For the measurements until 1991, the gas was passed into a Consolidated Engineering corporation (CEC) model 21-620 mass spectrometer and analyzed for nitrogen, methane, carbon dioxide, hydrogen, argon, water vapor, and higher hydrocarbons. Carbon monoxide could not initially be distinguished from nitrogen and was not reported. A VG Gas Analysis mass spectrometer, model 3001 equipped with electron multiplier detector, was obtained in 1990 to replace the CEC unit and provide better data. Carbon monoxide can now be detected in the nitrogen, and lower limits of detection exist for the oxygen measurements.

The data obtained are condensed in Table I below.

Table I. Methane and Carbon Dioxide Concentrations in Argonne Premium Coal Sample Ampoules.

\begin{tabular}{|c|c|c|c|c|c|c|c|c|c|c|c|}
\hline \multirow[t]{3}{*}{ Coal } & & \multicolumn{5}{|c|}{ - 100 mesh } & \multicolumn{5}{|c|}{-20 mesh } \\
\hline & \multirow{2}{*}{$\begin{array}{l}\text { major } \\
\text { gas }\end{array}$} & & $\mathrm{CH}_{4}$ & & \multicolumn{2}{|c|}{$\mathrm{CO}_{2}$ max. } & \multicolumn{2}{|c|}{$\mathrm{CH}_{4}$} & \multicolumn{3}{|c|}{$\mathrm{CO}_{2}$} \\
\hline & & tre & conc & time & trend & conc & trend & conc & time $t$ & end & conc \\
\hline UF & $\mathrm{CH}_{4}$. & + & .40 & 79 & + & .13 & $\mathbf{P}$ & .70 & 79 & + & .15 \\
\hline WY & $\mathrm{CO}_{2}$ & p. & .02 & 63 & P. & .93 & $\mathbf{P}$ & .02 & 63 & + & 1.4 \\
\hline IL & $\mathrm{CO}_{2}$ & P. & .23 & 65 & P. & .23 & P. & .46 & 65 & 0 & .66 \\
\hline PITT & $\mathrm{CH}_{4}$ & p. & .8 & 64 & P. & .58 & P. & 14.5 & 64 & 0 & 3.7 \\
\hline POC & $\mathrm{CH}_{4}$ & $\mathbf{P}$ & 1.2 & 62 & + & .78 & P. & 7.6 & 62 & $\mathbf{P}$ & 5.1 \\
\hline UT & $\mathrm{CO}_{2}$ & P. & .03 & 61 & + & .10 & 0 & .02 & 61 & P & .37 \\
\hline WV & $\mathrm{CO}_{2}$ & P. & .03 & 59 & + & .13 & P. & .23 & 59 & 0 & .53 \\
\hline ND & $\mathrm{CO}_{2}$ & P. & .02 & 58 & + & 2.68 & 0 & .03 & 58 & $\mathbf{P}$ & 3.3 \\
\hline
\end{tabular}

major gas = gas at higher concentration in ampoule (other than $\left.\mathrm{N}_{2}\right)$, trend $=$ trend of changes in concentration $(+=$ increasing, 0 = constant, - = decreasing, $\mathrm{P}=$ plateau before or after trend), P- = decrease after plateau, $\max$ conc = maximum concentration of gas in ampoule in $\%$, time = maximum time since sealing in months for data.

The data were plotted as concentration of gas versus time since sealing of the ampoules. Representative plots are shown in Figures 1-4. Figure 1 gives the concentration of $\mathrm{CH}_{4}$ versus time since sealing for -100 mesh material. Figure 2 gives a similar 
plot for the -20 mesh material. Figure 3 gives the concentration of $\mathrm{CO}_{2}$ versus time since sealing for -100 mesh material, while Figure 4 provides similar information for the -20 mesh material.

\section{RESULTS AND DISCUSSION:}

Differences in the gas contents were observed as time passed. Considerable amounts of methane were released during the initial size reduction in the sample processing facility. The gas contents in Table I represent subsequent gas releases. Lower rank (Beulah-zap and Wyodak-Anderson) and some intermediate rank (Illinois \#6, Blind Canyon, Lewiston-stockton) ampoules contained more carbon dioxide, while several higher rank (Pocahontas \#3, Upper Freeport, Pittsburgh seam) ampoules contained more methane.' In most cases, if carbon dioxide contents increased then methane contents did not increase, and vice-versa. oxygen contents remained at or below the limits of detection, indicating the integrity of the ampoules.

The data in Figure 1 indicate the variation in methane for the six most concentrated -100 mesh samples. In general, the concentration increases as the time since sealing increases. The highest rank coal, pocahontas, shows the largest methane concentration. The next highest rank, Upper Freeport, has a lower methane concentration than the pittsburgh seam (lower rank in this group). A comparison in a similar plot for -20 mesh particles for these three coals indicates the highest concentration for the Pittsburgh seam followed by the Pocahontas and Upper Freeport in that order. The data are more limited but show an increase with concentration with time. The maximum concentration for the Pittsburgh seam coal was about $14 \%$ of the gas volume, or more than an order of magnitude greater than for the -100 mesh material. For early measurements

The data in Figure 3 indicate the carbon dioxide content of the gas space in the ampoules above the -100 mesh lower rank samples. The Beulah-Zap sample (legend ND) clearly released the most carbon dioxide at $2.6 \%$. The Wyodak-Anderson sample released the next largest amount with the concentration increasing almost linearly over time. A similar plot of releases from -20 mesh material indicated that the evolution was only about $50 \%$ larger for the Beulah-zap material. The values for the other coals were two to three times as high. The concentrations for the remaining samples were Pittsburgh > Illinois \#6 > Lewiston-Stockton (legend WV) > Blind Canyon (legend UT). The latter three were relatively constant for the period in which the samples were analyzed.

The data in Figure 4 for -20 mesh samples indicate that the carbon dioxide concentrations are higher than those for the -100 mesh samples. This behavior is consistent with that observed for the methane measurements from the different particle sizes. The more striking difference is that the concentrations in the pocahontas and Pittsburgh samples have increased to exceed that from the Beulah-Zap sample.

It is believed that the gas is dissolved in the coal matter and is released very slowly. Bacterial activity is not considered responsible since either carbon dioxide or methane but generally 
not both are released from the samples, as might be expected from many bacterial actions. The most recent data indicate that significant quantities of carbon monoxide are not released in that the concentrations are at or below the limits of detection $(.02 \%)$.

CONCLUSIONS :

1. Higher rank coals evolve methane, and lower rank coals evolve carbon dioxide with some evolution of both gases for the intermediate ranks.

2. The evolution proceeds over times of years for pulverized coals in sealed ampoules.

3. Gas concentrations are higher above -20 mesh samples than above -100 mesh material.

4. Carbon monoxide is not evolved.

5. The Wyodak sample evolves carbon dioxide approximately linearly with time.

6. The gas evolution seems to be associated with evolution of dissolved species.

ACKNOWLEDGMENTS :

The author expresses his grateful appreciation to A. Engelkemier for her analyses of the coal ampoule atmospheres. Gratitude is also expressed to the U. S. Department of Energy, Office of Basic Energy Sciences, Chemical Sciences Division for support.

REFERENCES :

(1) Vorres, K. S., Proc. 1989 Intl. Conf. on Coal Science, Vol. II, 1083 (1989).

(2) Vorres, K. S., Proc. 1991 Intl. Conf. on Coal science, Vol. I, 147 (1991).

(3) Vorres, K. S., The Argonne Premium Coal Sample Program, Energy \& Fuels, 1990, 4, 420-426. 

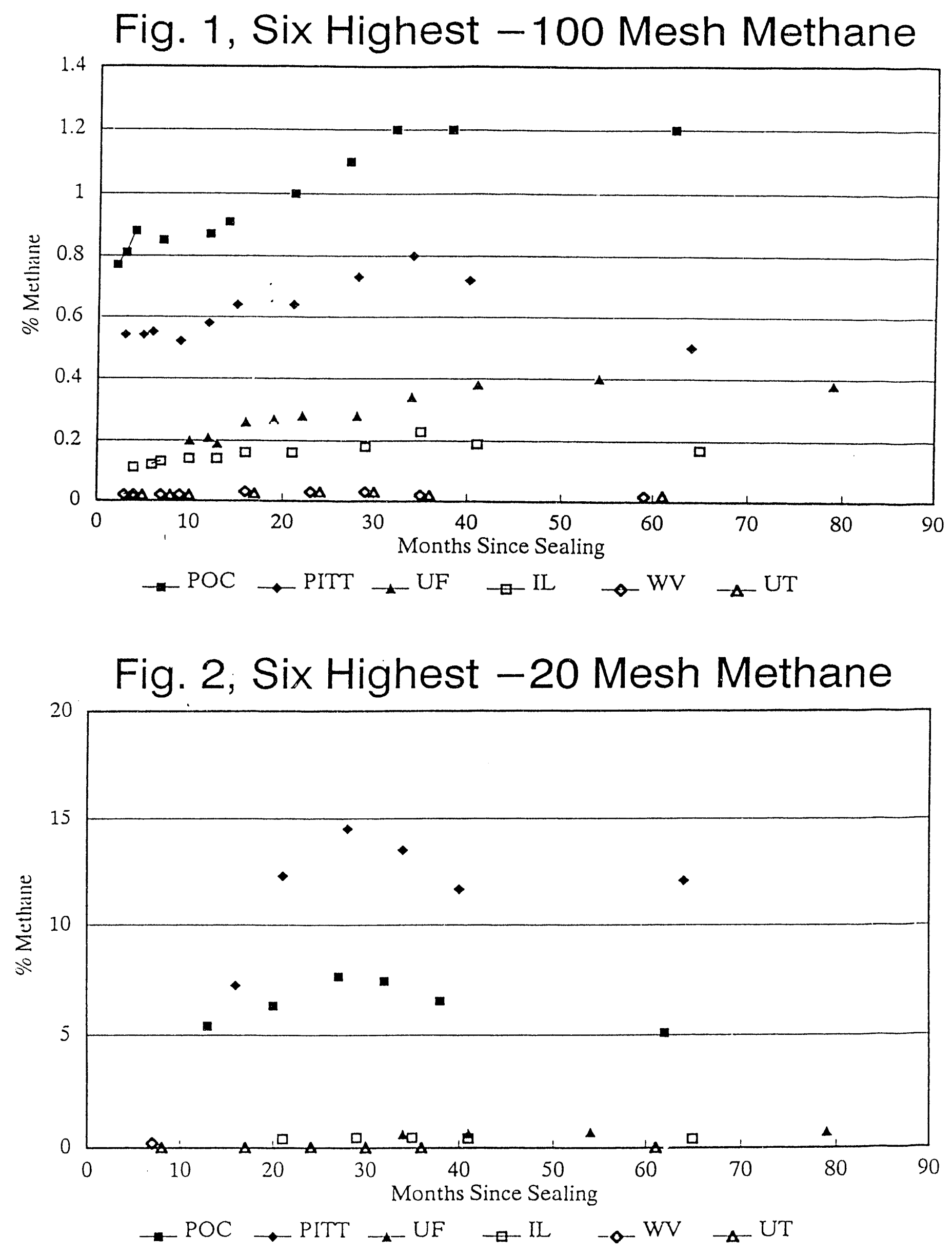

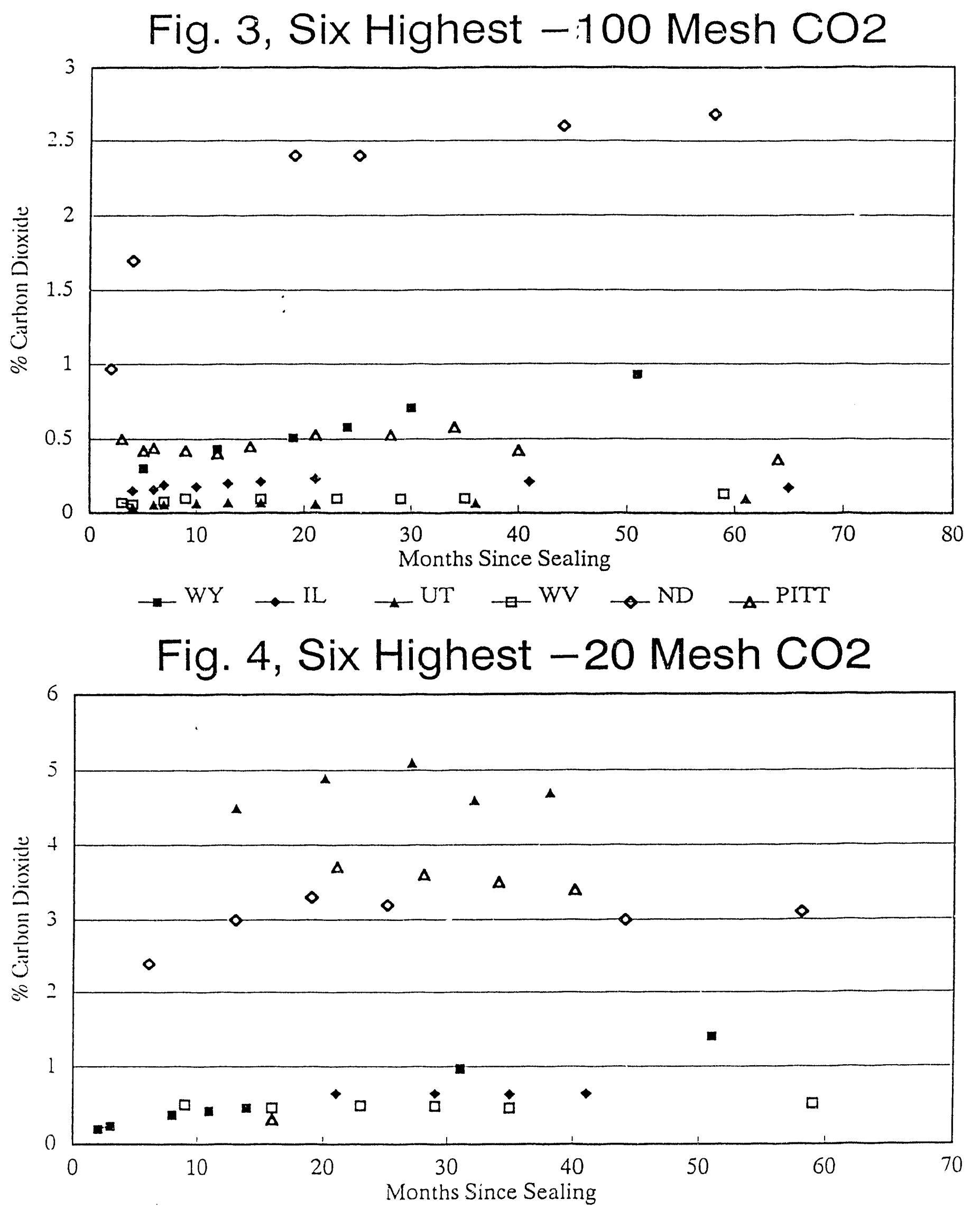

$\rightarrow W Y \rightarrow I I \quad \ldots P O C \rightarrow W V \multimap N D \rightarrow P I T T$ 

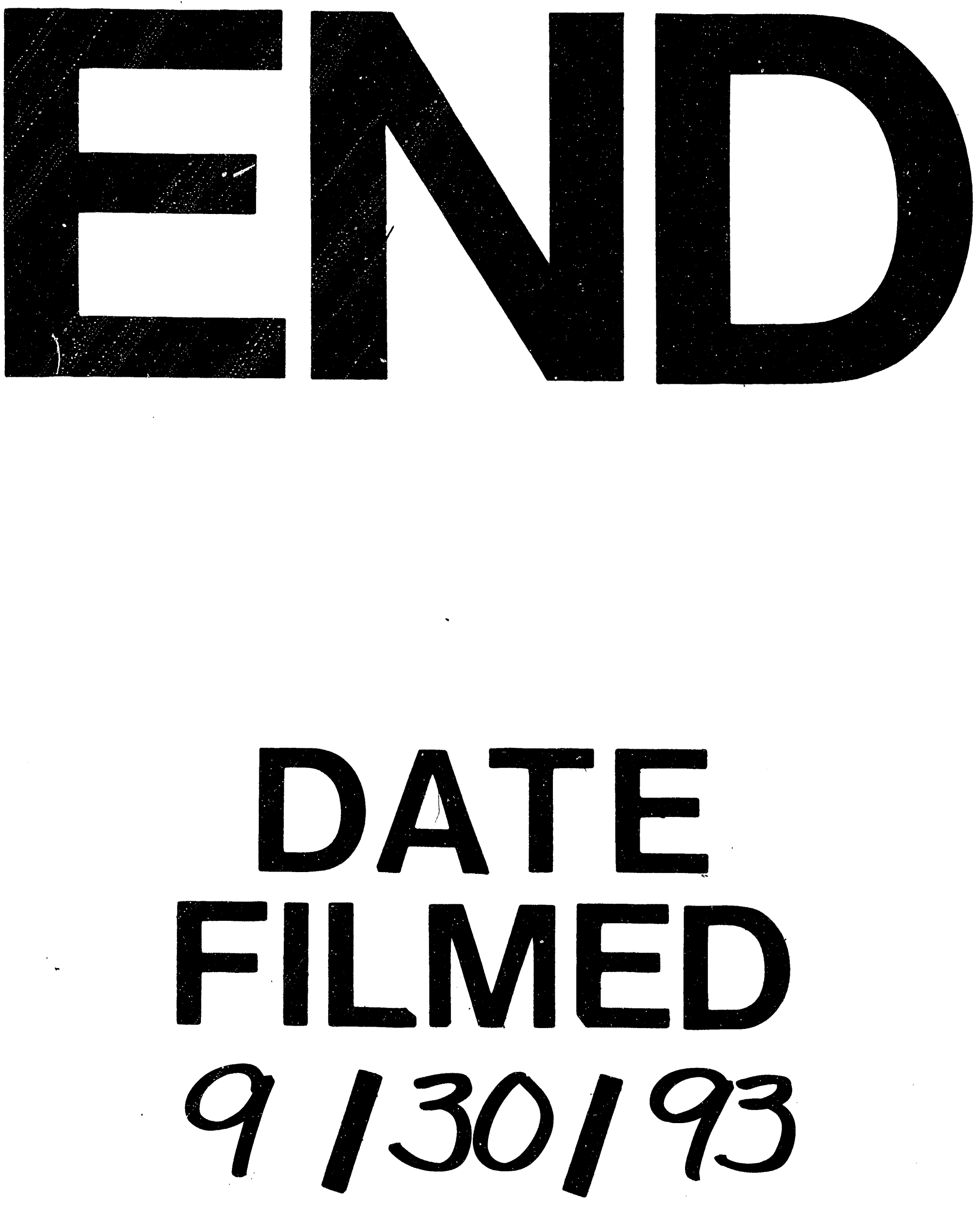
